\title{
Adult-Onset Henoch-Schonlein Purpura Duodenitis
}

\author{
Emmanuel Oforia ${ }^{a}$, Daryl Ramai ${ }^{\mathrm{a}, \mathrm{b}, \mathrm{e}}$, Mel A. Ona ${ }^{\mathrm{c}}$, Charilaos Papafragkakis ${ }^{\mathrm{d}}$, \\ Madhavi Reddy ${ }^{a}$
}

\begin{abstract}
Henoch-Schonlein purpura (HSP) is an immune-mediated vasculitis. HSP presents with purple spots on the skin (purpura), arthralgia, digestive problems, and kidney injury. HSP is most commonly seen in children, and rarely presents in adults. The pathogenesis involves the deposition of immune complexes in small to medium size blood vessels which leads to necrosis and inflammation. Most patients recover after symptomatic treatment, while more severe cases are treated with steroids. We report a 28 -year-old female patient who presented with two episodes of hematemesis, worsening abdominal pain, and bloody diarrhea. Physical examination showed erythematous, palpable, purpuric rashes on her thighs and lower legs. Contrast-enhanced computed tomography (CT) scan showed thickening of the duodenal wall, and upper endoscopy revealed mild gastric erythema and diffuse erythematous, hemorrhagic, friable mucosa with superficial, thick, adherent white exudate seen in the second portion of the duodenum, consistent with the diagnosis of HSP. We report on the clinical presentation of our patient, and review adult-onset HSP.
\end{abstract}

Keywords: Henoch-Schonlein purpura; Vasculitis; Duodenitis; Adult-onset; Gastrointestinal bleed

\section{Introduction}

Henoch-Schonlein purpura (HSP) is a systemic, small and medium sized vessel vasculitis that commonly affects children. Its occurrence in adults is unusual and estimated to be 13 per

Manuscript submitted August 29, 2017, accepted September 15, 2017

aDepartment of Gastroenterology and Hepatology, The Brooklyn Hospital Center, Academic Affiliate of the Icahn School of Medicine at Mount Sinai, Clinical Affiliate of the Mount Sinai Hospital, Brooklyn, NY, USA

bDepartment of Anatomical Sciences, St George's University School of Medicine, True Blue, Grenada, WI

'Division of Advanced Endoscopy, Cedars-Sinai Medical Center, Los Angeles, CA, USA

${ }^{\mathrm{d}}$ MD Anderson Cancer Center, Academic and Clinical Affiliate of the University of Texas, Houston, TX, USA

${ }^{e}$ Corresponding Author: Daryl Ramai, Department of Anatomical Sciences, St. George's University School of Medicine, Grenada, WI.

Email: dramai@sgu.edu

doi: https://doi.org/10.14740/jocmr3181w million population. The clinical presentation of HSP involves cutaneous palpable purpura, arthralgia/arthritis, bowel angina, and hematuria/proteinuria [1]. HSP with gastrointestinal (GI) involvement varies from mild symptoms to severe and lifethreatening complications such as perforation, acute mesenteric ischemia, and bowel infarction [2, 3]. GI manifestations of HSP occur in about $85 \%$ of cases [4]. HSP affects the small intestines with preference for the second portion of the duodenum [5]. The triggers are infections, medications, vaccines and malignancies, although causality remains unproven $[6,7]$. HSP in adults is estimated to occur in $3.4-14.3$ cases per million [8], a 20-fold fewer cases than in children. We report a rare case of adult-onset HSP presenting as GI bleeding and review the recent literature on this uncommon clinical entity.

\section{Case Report}

A 28-year-old female with medical history of chronic back pain, tendonitis and joint pains presented with two episodes of hematemesis, worsening abdominal pain, and bloody diarrhea. Additionally, the patient had arthralgia in her hands, wrists, and right knee. She reported daily use of non-steroidal antiinflammatory drugs for chronic back pain. Abdominal pain was diffuse, "cramping" in quality, intermittent, and radiated to the back. She reported passing a small amount of blood mixed with loose stool the morning of admission. She also noted an erythematous, non-pruritic rash on her lower legs. She denied fevers, sore throat, red or painful eyes, or prior bleeding episodes.

Physical examination revealed diffuse abdominal tenderness, no rebound tenderness, and no rigidity. Rectal exam revealed a small amount of blood mixed with scant yellowish stool. An erythematous palpable purpuric rash was observed on her thighs and lower legs (Fig. 1a). Abnormal blood tests included an elevated white cell count of $13,700 / \mathrm{mm}^{3}$, C-reactive protein (CRP) of $27.78 \mathrm{mg} / \mathrm{L}$, and D-dimer of $>35.2 \mathrm{mg} / \mathrm{L}$ (FEU), and complete blood count, comprehensive metabolic panel, coagulation profile, and urinalysis were normal.

Upper GI endoscopy revealed mild gastric erythema and diffuse erythematous, hemorrhagic, friable mucosa with superficial, thick, adherent white exudate seen in the second portion of the duodenum (Fig. 1b). Gastric and duodenal biopsies revealed mild reactive gastropathy (negative for Helicobacter pylori) and acute duodenitis, respectively. Contrast-enhanced computed tomography (CT) scan showed thickening of the duodenal wall (Fig. 1c). The patient was treated with proton pump inhibitor therapy and her abdominal pain resolved with 


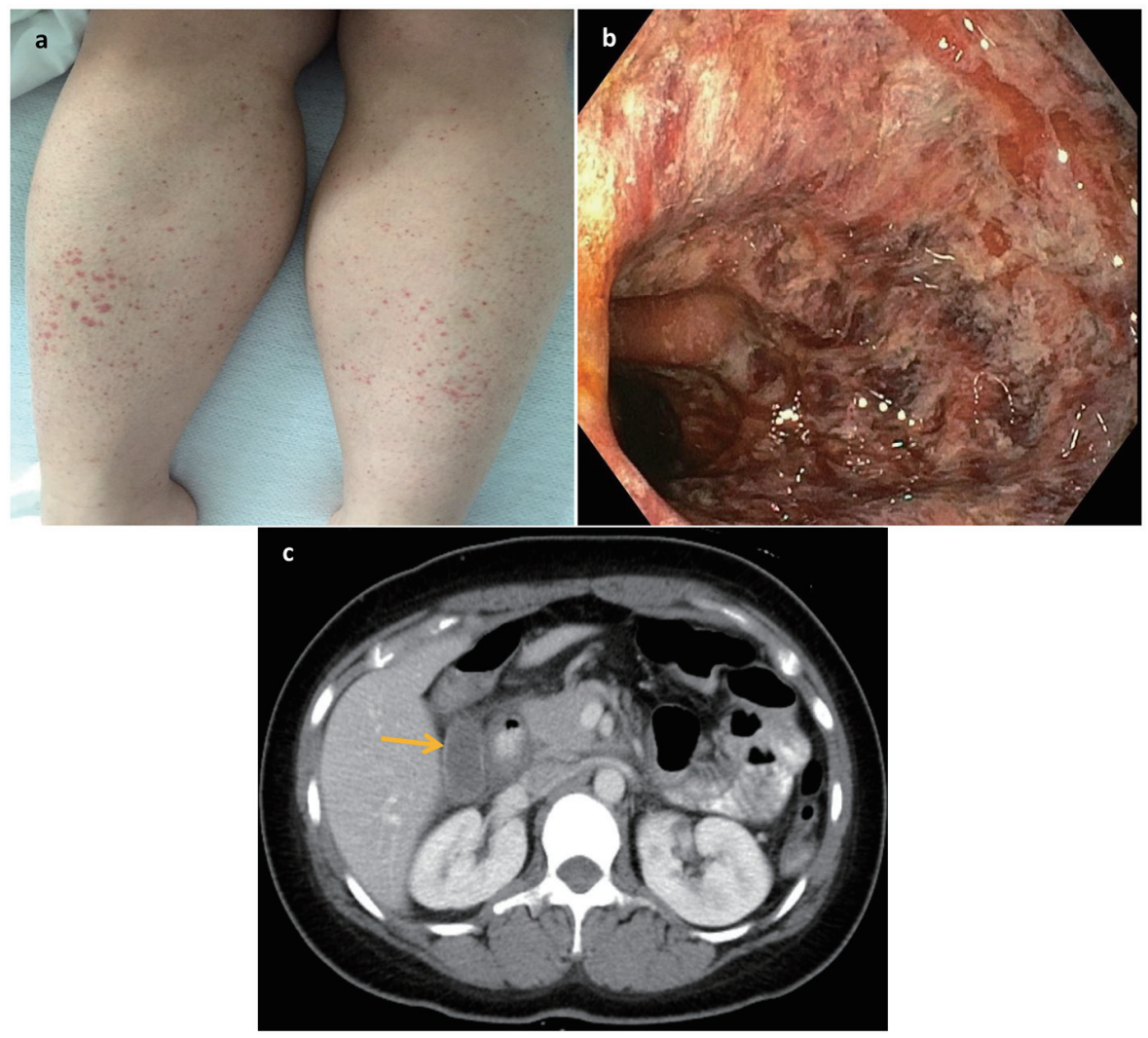

Figure 1. (a) Erythematous papules and palpable purpura on the lower extremities. (b) Diffuse erythematous, hemorrhagic, friable mucosa with superficial thick adherent white exudate seen in the second portion of the duodenum. (c) CT scan showed thickening of the duodenal wall representing duodenitis.

no further bleeding episodes. She was subsequently discharged after 3 days.

\section{Discussion}

Giant cell arteritis is the most common type of vasculitis in adults. HSP is the most common vasculitis in the pediatric population. In children less than 17 years of age, the incidence of HSP is $20 / 100,000$ with a minor male predilection $(\mathrm{M} / \mathrm{F}=$ 1.2/1.0). The peak age of incidence occurs between 4 and 6 years with the majority ( $90 \%$ ) of cases occurring before the age of 10 years. Globally, HSP commonly affects Asians, while in the United States, Caucasians have the highest incidence rate. In adults, the incidence of HSP is very rare (13/million) $[8,9]$. HSP is most commonly reported during late autumn to early spring seasons, though it can occur at any time [10].

In 2010, the European League Against Rheumatism/Pediatric Rheumatology International Trials Organization/Pediatric Rheumatology European Society proposed validated classification criteria for diagnosing HSP, among other vasculitis including childhood polyarteritis nodosa (c-PAN), c-Wegener granulomatosis (c-WG) and c-Takayasu arteritis (c-TA) [11]. A patient was classified as HSP in the presence of purpura or petechiae (mandatory) with lower limb predominance plus one of four criteria: 1) abdominal pain; 2) histopathology (im- munoglobulin A (IgA)); 3) arthritis or arthralgia; and 4) renal involvement. Our patient presented with palpable purpura, worsening abdominal pain, and arthralgia which fulfilled the diagnostic criteria for HSP.

HSP is an autoimmune disorder characterized by the deposition of IgA immune complexes in the walls of small to medium sized arteries [11]. Concomitantly vascular necrosis leads to extravasation of erythrocytes, infiltration of tissues with neutrophils, and deposition of degenerating neutrophil fragments called leukocytoclastic vasculitis (LCV). The extravasation of blood leads to the pathognomonic purpura of the skin, while inflammation and edema leads to swelling which is usually palpable [12]. Palpable purpura in the absence of thrombocytopenia is typically suggestive of HSP as it is found in almost all patients [10]. Purpura is usually noted in the legs and areas under pressure such as the buttocks. Other symptoms of HSP include abdominal pain and arthritis, though not universally present [5]. Renal involvement occurs in $32-54 \%$ of patients, and in most instances, it manifests as hematuria [13]. These patients are at increased risk for chronic renal failure, and should be monitored with weekly urinalysis throughout the disease process [14].

HSP immune complex formation can be triggered by infectious antigens, medications, tumors, or other environmental factors. Upper respiratory tract infections have been reported to occur in $35-52 \%$ of patients [15]. Group A streptococcus 
cultures have been found positive in more than $30 \%$ of children with Henoch-Schonlein nephritis, and positive serum antistreptolysin-O titers [16]. Other suspected viral and bacterial activators include parvovirus B19, Bartonella henselae, Helicobacter pylori, Haemophilus parainfluenza, Coxsackie virus, adenovirus, hepatitis A and B viruses, mycoplasma, EpsteinBarr virus, varicella, campylobacter, and methicillin-resistant Staphylococcus aureus [17-20].

HSP with GI involvement varies from mild to severe and life-threatening complications. The small intestinal epithelial villi are most commonly affected due to the presence of end capillaries, making it susceptible to ischemic injury. Usually, skin manifestations precede GI manifestations, but in onefourth of cases, skin lesions occur after GI manifestations. Abdominal pain, which is colicky and worse with food, is the most common GI symptom occurring in $60-65 \%$ of patients [14]. Vomiting and GI bleeding develop in about 30\% of patients [21]. Rarely, intussusception (ileoleal), ischemic necrosis of the bowel wall, intestinal perforation, acute acalculous cholecystitis, hemorrhagic ascites with serositis, pancreatitis, and biliary cirrhosis may occur [21-25].

Endoscopic findings reflective of HSP include erythema, swelling, petechiae, erosions, ulcers, purpura, and submucosal hemorrhage [26]. Patients can also present with duodenitis, where the second portion of the duodenum is most commonly involved. Ulcers are commonly seen in the rectum and ileum where it is most severe. Isolated cases have described the effect of HSP on the colon as multiple petechiae either grouped along the longitudinal striae of the colon or dispersed randomly. In contrast to the duodenum, there does not appear to be any characteristic site of involvement in the colon [27, 28]. When HSP of the GI tract is suspected, and where all typical investigative modalities are negative, capsule endoscopy may aid in surveillance and diagnosis [29]. Since upper endoscopy was able to identify hemorrhagic small bowel mucosa, capsule endoscopy was not indicated. Enteroscopy may be used to investigate the jejunum if the duodenum is normal [30]. Furthermore, endoscopic ultrasound (EUS) may show mucosal and submucosal thickening without affecting the muscularis layer [31]. CT scan may also show thickening of the bowel walls, as seen in our patient.

HSP is a self-limiting disease, where treatment is mainly supportive [14]. The use of non-steroidal anti-inflammatory drugs (NSAIDs) is effective in relieving arthritic symptoms, and abdominal pain. However, in cases of concurrent GI ulcers, NSAIDs may exacerbate this condition. Glucocorticoids and other steroids have been successfully used to treat HSP by alleviating abdominal pain and decreasing the likelihood of intussusception [32, 33]. However, glucocorticoids have not been shown to decrease the renal complications associated with HSP [34].

\section{Conclusion}

HSP most commonly affects the pediatric population and rarely affects adults. Clinicians should be aware of the clinical presentation of HSP, and its triggers in order to rapidly diagnose and treat affected patients. We suspected HSP in our patient due to the presence of palpable purpura, diffuse abdominal pain with GI bleeding, and arthralgia. Secondly, HSP had a predominant effect on the small bowel, particularly in the second portion of the duodenum with characteristic endoscopic findings of diffuse erythema, and hemorrhagic and friable mucosa. Fortunately, our patient recovered with supportive treatment, and had a favorable clinical outcome.

\section{Author Contributions}

Conception and design: Emmanuel Ofori, Daryl Ramai, Mel A. Ona, Charilaos Papafragkakis, and Madhavi Reddy. Drafting of the article: Emmanuel Ofori, Daryl Ramai, Mel A. Ona, Charilaos Papafragkakis, and Madhavi Reddy. Critical revision of the article for important intellectual content: Emmanuel Ofori, Daryl Ramai, and Madhavi Reddy. Final approval of the article: Emmanuel Ofori, Daryl Ramai, Mel A. Ona, Charilaos Papafragkakis, and Madhavi Reddy.

\section{Funding}

None.

\section{Conflict of Interest}

None.

\section{References}

1. Yang $\mathrm{YH}, \mathrm{Yu} \mathrm{HH}$, Chiang BL. The diagnosis and classification of Henoch-Schonlein purpura: an updated review. Autoimmun Rev. 2014;13(4-5):355-358.

2. Collins DA, Duke O. Systemic vasculitis presenting with massive bowel infarction. J R Soc Med. 1995;88(12):692693.

3. Mosley JG, Desai A, Gupta I. Mesenteric arteritis. Gut. 1990;31(8):956-957.

4. Szer IS. Henoch-Schonlein purpura: when and how to treat. J Rheumatol. 1996;23(9):1661-1665.

5. Ebert EC. Gastrointestinal manifestations of HenochSchonlein Purpura. Dig Dis Sci. 2008;53(8):2011-2019.

6. Chang WL, Yang YH, Lin YT, Chiang BL. Gastrointestinal manifestations in Henoch-Schonlein purpura: a review of 261 patients. Acta Paediatr. 2004;93(11):14271431.

7. Sola Alberich R, Jammoul A, Masana L. Henoch-Schonlein purpura associated with acetylsalicylic acid. Ann Intern Med. 1997;126(8):665.

8. Watts RA, Scott DG. Epidemiology of the vasculitides. Semin Respir Crit Care Med. 2004;25(5):455-464.

9. Roberts PF, Waller TA, Brinker TM, Riffe IZ, Sayre JW, Bratton RL. Henoch-Schonlein purpura: a review article. South Med J. 2007;100(8):821-824.

10. Gedalia A. Henoch-Schonlein purpura. Curr Rheumatol 
Rep. 2004;6(3):195-202.

11. Ozen S, Pistorio A, Iusan SM, Bakkaloglu A, Herlin T, Brik R, Buoncompagni A, et al. EULAR/PRINTO/PRES criteria for Henoch-Schonlein purpura, childhood polyarteritis nodosa, childhood Wegener granulomatosis and childhood Takayasu arteritis: Ankara 2008. Part II: Final classification criteria. Ann Rheum Dis. 2010;69(5):798806.

12. Micheletti RG, Werth VP. Small vessel vasculitis of the skin. Rheum Dis Clin North Am. 2015;41(1):21-32, vii.

13. Sano H, Izumida M, Shimizu H, Ogawa Y. Risk factors of renal involvement and significant proteinuria in HenochSchonlein purpura. Eur J Pediatr. 2002;161(4):196-201.

14. Saulsbury FT. Clinical update: Henoch-Schonlein purpura. Lancet. 2007;369(9566):976-978.

15. Blanco R, Martinez-Taboada VM, Rodriguez-Valverde V, Garcia-Fuentes M, Gonzalez-Gay MA. Henoch-Schonlein purpura in adulthood and childhood: two different expressions of the same syndrome. Arthritis Rheum. 1997;40(5):859-864.

16. Masuda M, Nakanishi K, Yoshizawa N, Iijima K, Yoshikawa N. Group A streptococcal antigen in the glomeruli of children with Henoch-Schonlein nephritis. Am J Kidney Dis. 2003;41(2):366-370.

17. Finkel TH, Torok TJ, Ferguson PJ, Durigon EL, Zaki SR, Leung DY, Harbeck RJ, et al. Chronic parvovirus B19 infection and systemic necrotising vasculitis: opportunistic infection or aetiological agent? Lancet. 1994;343(8908):1255-1258.

18. Jennette JC, Falk RJ. Small-vessel vasculitis. N Engl J Med. 1997;337(21):1512-1523.

19. Eftychiou C, Samarkos M, Golfinopoulou S, Skoutelis A, Psarra A. Henoch-Schonlein purpura associated with methicillin-resistant Staphylococcus aureus infection. Am J Med. 2006;119(1):85-86.

20. Yang YH, Chuang YH, Wang LC, Huang HY, Gershwin ME, Chiang BL. The immunobiology of Henoch-Schonlein purpura. Autoimmun Rev. 2008;7(3):179-184.

21. Bailey M, Chapin W, Licht H, Reynolds JC. The effects of vasculitis on the gastrointestinal tract and liver. Gastroenterol Clin North Am. 1998;27(4):747-782, v-vi.

22. Ebina K, Kato S, Abukawa D, Nakagawa H. Endoscopic hemostasis of bleeding duodenal ulcer in a child with He-
noch-Schonlein purpura. J Pediatr. 1997;131(6):934-936.

23. Archimandritis A, Kalos A, Pantzos A, Sakellariou D, Malamas N, Fertakis A. Hemorrhagic ascites in a patient with anaphylactoid purpura. J Clin Gastroenterol. 1994;18(3):257-258.

24. Wu CS, Tung SY. Henoch-Schonlein purpura complicated by upper gastrointestinal bleeding with an unusual endoscopic picture. J Clin Gastroenterol. 1994;19(2):128131.

25. Viola S, Meyer M, Fabre M, Tounian P, Goddon R, Dechelotte P, Valayer J, et al. Ischemic necrosis of bile ducts complicating Schonlein-Henoch purpura. Gastroenterology. 1999;117(1):211-214.

26. Esaki M, Matsumoto T, Nakamura S, Kawasaki M, Iwai K, Hirakawa K, Tarumi K, et al. GI involvement in Henoch-Schonlein purpura. Gastrointest Endosc. 2002;56(6):920-923.

27. Tomomasa T, Hsu JY, Itoh K, Kuroume T. Endoscopic findings in pediatric patients with Henoch-Schonlein purpura and gastrointestinal symptoms. J Pediatr Gastroenterol Nutr. 1987;6(5):725-729.

28. Banerjee B, Rashid S, Singh E, Moore J. Endoscopic findings in Henoch-Schonlein purpura. Gastrointest Endosc. 1991;37(5):569-571.

29. Stancanelli B, Vita A, Vinci M, Magnano A, Purrello F. Bleeding of small bowel in Henoch-Schonlein syndrome: the successful diagnostic role of video capsule endoscopy. Am J Med. 2006;119(1):82-84.

30. Preud'Homme DL, Michail S, Hodges C, Milliken T, Mezoff AG. Use of wireless capsule endoscopy in the management of severe Henoch-Schonlein purpura. Pediatrics. 2006;118(3):e904-906.

31. Tai CM, Liou JM, Tsai MC, Wang HP. EUS features of duodenal lesions in Henoch-Schonlein purpura. Gastrointest Endosc. 2005;62(2):307; discussion 307.

32. Reamy BV, Williams PM, Lindsay TJ. Henoch-Schonlein purpura. Am Fam Physician. 2009;80(7):697-704.

33. Weiss PF, Feinstein JA, Luan X, Burnham JM, Feudtner C. Effects of corticosteroid on Henoch-Schonlein purpura: a systematic review. Pediatrics. 2007;120(5):10791087.

34. Dillon MJ. Henoch-Schonlein purpura: recent advances. Clin Exp Rheumatol. 2007;25(1 Suppl 44):S66-68. 